\title{
Effect of Solvent Type on the Nanoparticle Formation of Atorvastatin Calcium by the Supercritical Antisolvent Process
}

\author{
Min-Soo Kim, ${ }^{a}$ Ha-Seung Song, ${ }^{a}$ Hee Jun Park,,${ }^{a, c}$ and Sung-Joo Hwang $*, b, c$ \\ ${ }^{a}$ College of Pharmacy, Chungnam National University; 220 Gung-dong, Yuseong-gu, Daejeon 305-764, Republic \\ of Korea: ${ }^{b}$ College of Pharmacy, Yonsei University: and ${ }^{c}$ Yonsei Institute of Pharmaceutical Sciences, Yonsei \\ University; 162-1 Songdo-dong, Yeonsu-gu, Incheon 406-840, Republic of Korea. \\ Received October 6, 2011; accepted January 19, 2012; published online January 25, 2012
}

The aims of this study were to identify how the solvent selection affects particle formation and to examine the effect of the initial drug solution concentration on mean particle size and particle size distribution in the supercritical antisolvent (SAS) process. Amorphous atorvastatin calcium was precipitated from seven different solvents using the SAS process. Particles with mean particle size ranging between 62.6 and $1493.7 \mathrm{~nm}$ were obtained by varying organic solvent type and solution concentration. By changing the solvent, we observed large variations in particle size and particle size distribution, accompanied by different particle morphologies. Particles obtained from acetone and tetrahydrofuran (THF) were compact and spherical fine particles, whereas those from $N$-methylpyrrolidone (NMP) and dimethylsulfoxide (DMSO) were agglomerated, with rough surfaces and relatively larger particle sizes. Interestingly, the mean particle size of atorvastatin calcium increased with an increase in the boiling point of the organic solvent used. Thus, for atorvastatin particle formation via the SAS process, particle size was determined mainly by evaporation of the organic solvent into the antisolvent phase. In addition, the mean particle size was increased with increasing drug solution concentration. In this study, from the aspects of particle size and solvent toxicity, acetone was the better organic solvent for controlling nanoparticle formation of atorvastatin calcium.

Key words atorvastatin; nanoparticle; supercritical antisolvent; amorphous

A new approach in particle engineering developed to obtain micro/nanoparticles with peculiar characteristics is represented by the supercritical fluid technology. ${ }^{1}$ Among the several types of supercritical fluid processes, supercritical antisolvent (SAS) process have some advantages such as easy handling of difficult-to-comminute materials, use of a nontoxic medium, and a mild operating temperature may provide ideal conditions for the processing of pharmaceutical compounds. Moreover, fast diffusion of supercritical antisolvent into the liquid solvent produces the supersaturation of the solute and its precipitation in micronized particles down to particle diameters, and control of the particle size distribution is also possible. ${ }^{2,3)}$ Many researchers have been studied that the morphology, crystallinity, particle size and particle size distribution can be controlled through the changing of various process conditions such as temperature, pressure, solvent, drug solution concentration, solution to antisolvent flow rate ratio, and the rate of mass transfer in SAS process. ${ }^{4-9)}$

Previously, we investigated the effect of SAS process parameters such as the pressure, temperature, and feed rate ratio of $\mathrm{CO}_{2} / \mathrm{drug}$ solution on the particle formation of atorvastatin calcium using methanol as a solvent. ${ }^{10)}$ In addition, we reported the usefulness of the amorphous nanoparticles as a method of enhancing the supersaturation, dissolution, and absorption properties of atorvastatin. ${ }^{11)}$ However, methanol is an International Conference on Harmonization (ICH) class 2 solvent and is toxic. Here, we precipitated atorvastatin calcium from various ICH class 3 solvents, including acetic acid, acetone and dimethylsulfoxide (DMSO). The aims of this study were to identify how the solvent selection affects particle formation and to examine the effect of the initial drug solution concentration on mean particle size and particle size distribution.

\section{Experimental}

Materials Atorvastatin calcium was obtained from Zhejiang Jiangbei Pharmaceutic (China). Carbon dioxide $\left(\mathrm{CO}_{2}\right)$ with high purity of $99.9 \%$ was supplied from Hanmi Gas Co., Ltd. (South Korea). Acetic acid, acetone and tetrahydrofuran (THF) were purchased from J. T. Baker (U.S.A.). DMSO (purity 99.5\%), $N$-methylpyrrolidone (NMP, 99.5\%), N,Ndimethylacetamide (DMA, 99\%) and $N, N$-dimethylformamide (DMF, 99.8\%) were purchased from Sigma-Aldrich (Korea).

Micronization of Atorvastatin Calcium The SAS apparatus used is made up of the follow components: two high pressure pump; circulator and cooling lines for keeping $\mathrm{CO}_{2}$, which flows out of storage tank and $\mathrm{CO}_{2}$ pump head cold $\left(-10^{\circ} \mathrm{C}\right)$; a pre-vessel with electric heating jacket; a precipitation vessel (1.9L) with water jacket and separator vessel (0.6L); two manual back pressure regulators (Tescom, model 26-1723-24-194). Further information on the SAS apparatus was published elsewhere. ${ }^{10)}$ Briefly, using a homemade plunger

Table 1. Summary of Experiments Performed

\begin{tabular}{lcc}
\hline \hline Solvent & Concentration $(\mathrm{mg} / \mathrm{mL})$ & Particle size $^{a)}(\mathrm{nm})$ \\
\hline Acetone & 100 & $62.6 \pm 13.2$ \\
Acetone & 200 & $133.5 \pm 25.2$ \\
Acetone & 300 & $179.7 \pm 27.1$ \\
THF & 100 & $91.1 \pm 19.7$ \\
THF & 200 & $263.3 \pm 35.5$ \\
THF & 300 & $348.5 \pm 60.5$ \\
Acetic acid & 100 & $360.6 \pm 32.3$ \\
DMA & 100 & $553.6 \pm 42.2$ \\
DMF & 100 & $506.3 \pm 43.6$ \\
DMSO & 100 & $874.5 \pm 224.1$ \\
NMP & 100 & $1493.7 \pm 189.2$ \\
\hline
\end{tabular}

a) Mean particle size calculated by cumulant method using dynamic light scattering measurement $(n=3$, mean \pm S.D.). 
(a)

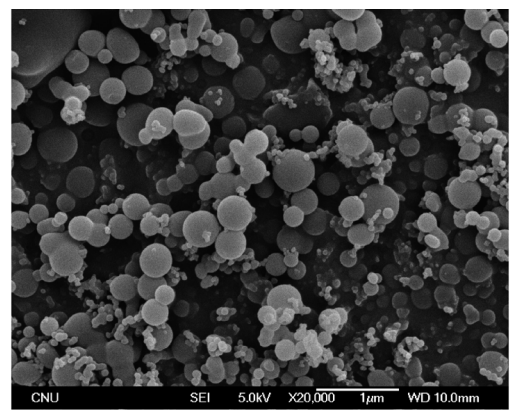

(c)

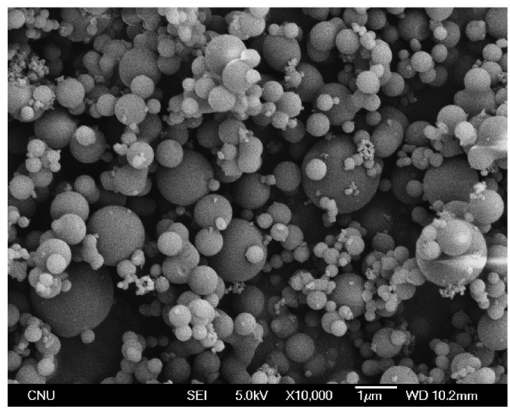

(e)

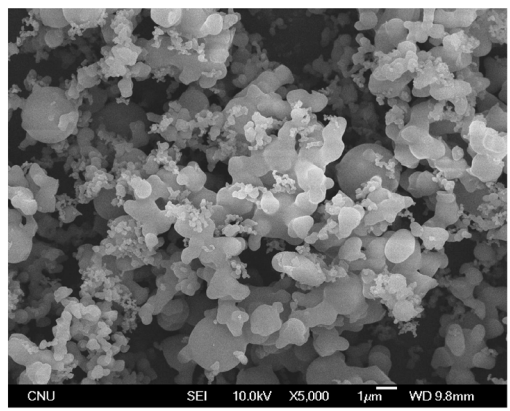

(g)

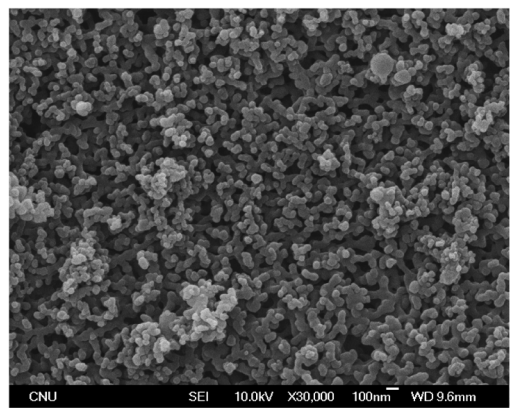

(b)

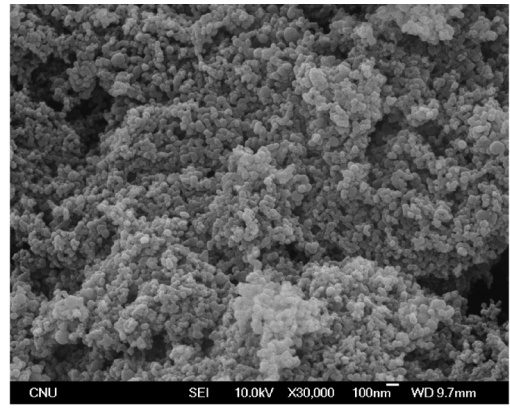

(d)

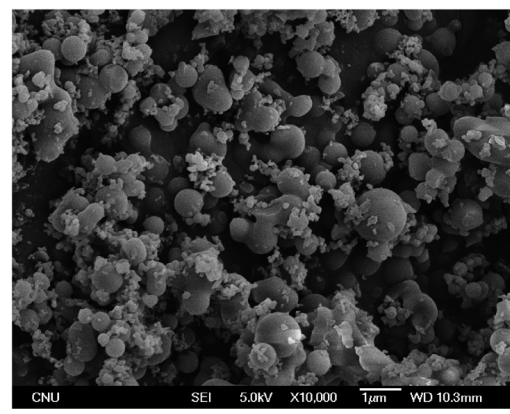

(f)

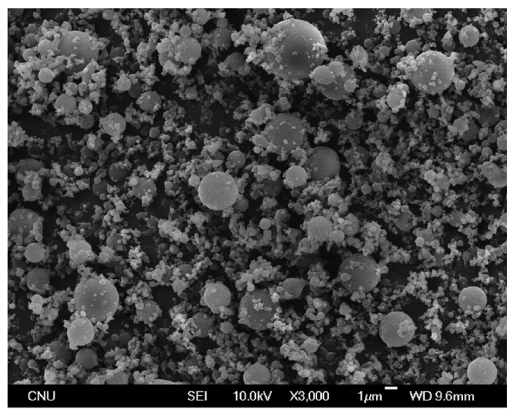

Fig. 1. SEM Images of Atorvastatin Calcium Precipitated from Acetic Acid (a), Acetone (b), DMA (c), DMF (d), DMSO (e), NMP (f) and THF (g)

pump, $\mathrm{CO}_{2}$ was delivered at a constant rate through the outer capillary of the two-flow spray nozzle and into the top of a particle precipitation vessel, until the desired pressure was reached. Atorvastatin calcium was dissolved in organic solvent and sprayed into the particle precipitation vessel via the inner capillary of the two-flow spray nozzle, using an HPLC liquid pump. During particle precipitation, the operating pressure and temperature were fixed at $40^{\circ} \mathrm{C}$ and $12 \mathrm{MPa}$, respectively, on the basis of our previous experience. The flow rates of supercritical $\mathrm{CO}_{2}$ and the drug solution were $45 \mathrm{~g} / \mathrm{min}$ and $0.5 \mathrm{~g} /$ min, respectively. After the spraying of the drug solution was complete, fresh supercritical $\mathrm{CO}_{2}$ was introduced into the ves- sel at the same rate for $1 \mathrm{~h}$, to remove residual solvent solubilized in the supercritical antisolvent.

Analysis and Characterization The morphology and shape of particles was characterized using scanning electron microscopy (SEM; JSM-7000F, Jeol Ltd., Japan) at $10 \mathrm{kV}$ accelerating voltage. Samples were coated with gold and palladium using a vacuum evaporator before SEM analysis. To determine the particle size and particle size distribution of samples, dynamic light scattering (DLS) measurements were carried out using electrophoretic light scattering spectrophotometer (ELS-8000, Otsuka Electronics, Japan). The samples were dispersed in mineral oil (Macrol 52, Exxon Mobil Co., U.S.A.) 
and then sonicated for $10 \mathrm{~min}$ at $120 \mathrm{~W}$ before DLS measurements. Powder X-ray diffraction patterns of the samples were recorded on a Rigaku Powder X-ray diffraction system, Model D/MAX-2200 Ultima/PC (Japan) with Ni-filtered $\mathrm{CuK \alpha}$ radiation over the interval $5-60^{\circ} / 2 \theta$. The step scan mode was performed with a step size of $0.02^{\circ}$ at a rate of $3 \% \mathrm{~min}$.

\section{Results and Discussion}

As in liquid antisolvent precipitation, the success of the SAS micronization process depends on the solubility of the liquid solvent in the supercritical antisolvent and the insolubility of the solute in the antisolvent. For the controlled precipitation of atorvastatin calcium using the SAS process, it is not known which liquid solvent is most suitable. Therefore, we investigated the effect of seven different solvents (acetone, acetic acid, DMA, DMF, DMSO, NMP and THF) on mean particle size and particle distribution. These solvents were selected for their high capacity to solubilize atorvastatin calcium $(>100 \mathrm{mg} / \mathrm{mL})$. The experimental conditions and mean particle sizes following the SAS process are summarized in Table 1. All experimental yields were greater than 90\%. A substantial amount of vapor-liquid equilibria and volumetric expansion data have been published for the $\mathrm{CO}_{2}$-solvent binary system. ${ }^{12-14)}$ The position of the operating point is in the supercritical region and is very far from the mixture critical point pressure in the vapor-liquid equilibria data for each solvent- $\mathrm{CO}_{2}{ }^{15-18)}$ These operating conditions ensure complete

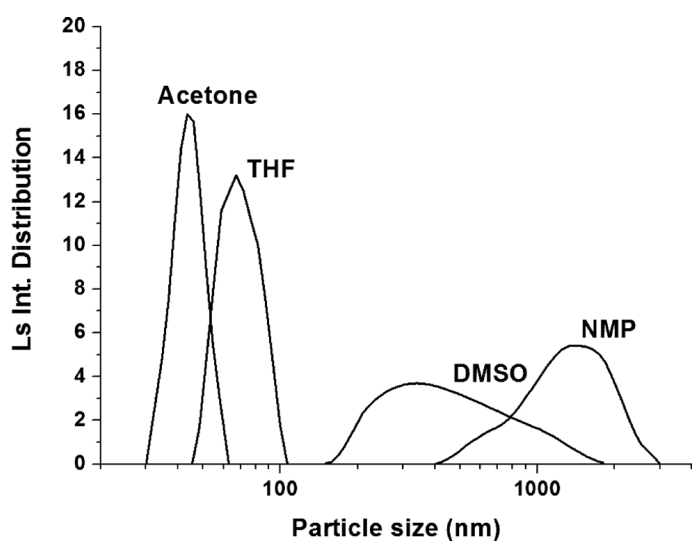

Fig. 2. Particle Size Distribution of Atorvastatin Calcium Precipitated from Acetone, DMSO, NMP and THF miscibility between the organic solvent and $\mathrm{CO}_{2}$.

Effect of Solvents As shown in Fig. 1, particles obtained from acetone and THF were compact and spherical fine particles, whereas those from NMP and DMSO were agglomerated, with rough surfaces and relatively larger particle sizes. The mean particle sizes of particles precipitated from acetic acid, acetone, DMA, DMF, NMP, DMSO, and THF were $360.6,62.6,553.6,506.3,874.5,1493.7$ and $91.1 \mathrm{~nm}$, respectively. In addition, the particle size distributions of particles precipitated from acetone and THF were narrower than those of particles precipitated from DMSO and NMP (Fig. 2).

These results are attributed to the differences in chemical properties between the organic solvents and carbon dioxide, and the properties of the solvents (Table 2). Essentially, $\mathrm{CO}_{2}$ behaves as a nonpolar solvent and is most soluble in the least polar solvent. Thus, at a given pressure, the level of volumetric expansion is greater for a less polar solvent than for a more polar solvent. Previously, Reverchon and coworkers reported that small spherical nanoparticles were produced from solvents that have large volume expansions. ${ }^{19)}$ In the present study, the particles precipitated from acetone and THF had relatively low dipole moments compared with those of particles precipitated from DMSO and NMP.

The present results were also interpreted according to solubility parameter. ${ }^{20)}$ In the SAS process, nucleation and crystal growth took place within the environment of a mixture of organic solvents and carbon dioxide. Considering the solubility parameter, when the intermolecular forces of organic solvents and carbon dioxide are similar, it is easy for each molecule to interact. As the difference in solubility parameters between the organic solvent and carbon dioxide decreases, the rate of nucleation may increase, resulting in a smaller precipitated particle size. In this study, the solubility parameter of supercritical $\mathrm{CO}_{2}$ was about $18.3 \mathrm{MPa}^{1 / 2}\left(40^{\circ} \mathrm{C}, 12 \mathrm{MPa}\right){ }^{21)}$ The solubility parameter of all of the solvents used was greater than that of supercritical $\mathrm{CO}_{2}$ : for acetic acid, acetone, DMA, DMF, DMSO, NMP and THF the values were 21.4, 20.0, 22.7, 24.8, 26.7, 22.9 and $19.4 \mathrm{MPa}^{1 / 2}$, respectively. ${ }^{22)}$ The mean particle size decreased with the solubility parameter of the organic solvent, indicating that particle size decreases as the solubility parameter of the organic solvent approaches that of supercritical $\mathrm{CO}_{2}$ (Fig. 3a). Thus, it may be possible to manipulate particle size by the appropriate selection of an organic solvent based on solubility parameter.

Table 2. Properties of Organic Solvents

\begin{tabular}{|c|c|c|c|c|c|c|c|}
\hline \multirow{2}{*}{ Solvent } & \multirow{2}{*}{$T_{\mathrm{b}}\left({ }^{\circ} \mathrm{C}\right)$} & \multirow{2}{*}{$\begin{array}{l}\text { Dipolar moment } \\
\text { (D) }\end{array}$} & \multirow{2}{*}{$\begin{array}{c}\text { Dielectric constant } \\
(\varepsilon)\end{array}$} & \multicolumn{4}{|c|}{ Hansen parameters $\left(\mathrm{MPa}^{1 / 2}\right)$} \\
\hline & & & & $\delta_{\mathrm{t}}$ & $\delta_{\mathrm{d}}$ & $\delta_{\mathrm{p}}$ & $\delta_{\mathrm{h}}$ \\
\hline Acetic acid & 117.9 & 1.68 & 6.15 & 21.4 & 14.5 & 8 & 13.5 \\
\hline Acetone & 56.1 & 2.69 & 20.56 & 20 & 15.5 & 10.4 & 7 \\
\hline DMA & 166.2 & 3.72 & 37.78 & 22.7 & 16.8 & 11.5 & 10.2 \\
\hline DMF & 153.1 & 3.82 & 36.71 & 24.8 & 17.4 & 13.7 & 11.3 \\
\hline DMSO & 189.1 & 4.06 & 46.45 & 26.7 & 18.4 & 16.4 & 10.2 \\
\hline NMP & 201.9 & 4.09 & 32.2 & 22.9 & 18 & 12.3 & 7.2 \\
\hline THF & 66 & 1.75 & 7.58 & 19.4 & 16.8 & 5.7 & 8 \\
\hline $\begin{array}{l}\text { Supercritical } \\
\mathrm{CO}_{2}\end{array}$ & - & - & - & 18.3 & 16.3 & 4.4 & 7.1 \\
\hline
\end{tabular}

$T_{\mathrm{b}}$ (boiling point), dipolar moment and dielectric constant of solvents, listed from Marcus. ${ }^{26)}$ Hansen parameter $\left(\delta_{\mathrm{t}}\right.$ : total Hildebrand parameter, $\delta_{\mathrm{d}}:$ dispersion component, $\delta_{\mathrm{p}}$ : polar component, $\delta_{\mathrm{h}}$ : hydrogen bonding component) of solvents, listed from Burke. ${ }^{22)}$ The supercritical $\mathrm{CO}_{2}$ solubility parameter at $40^{\circ} \mathrm{C}$ and $12 \mathrm{MPa}$ was obtained from internet site. $^{21}$ 
(a)

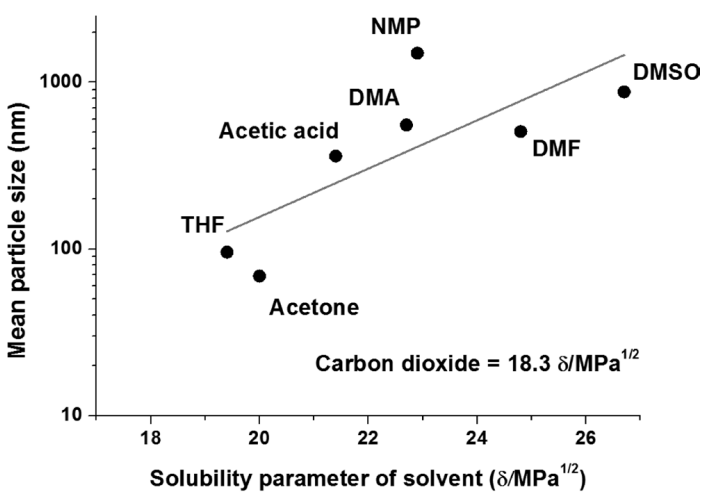

(b)

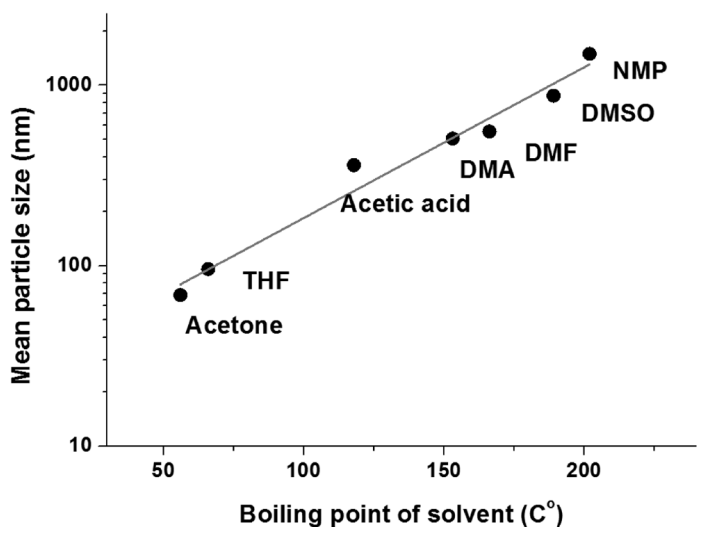

Fig. 3. Correlation of Mean Particle Size with Total Hildebrand Solubility Parameter (a) and Boiling Point (b) of Organic Solvents

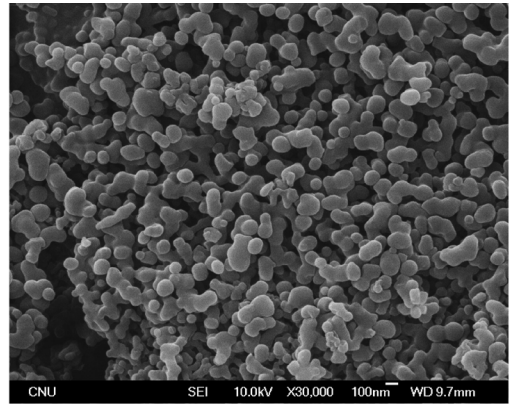

(a)

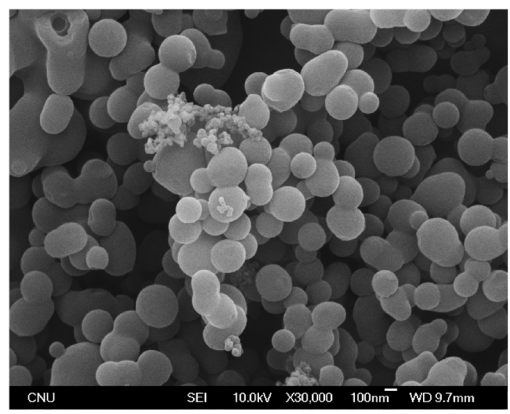

In the SAS process, morphology and particle size are dominated by the mechanisms of organic solvent evaporation into the antisolvent phase and antisolvent diffusion into the organic solvent. $^{23,24)}$ Interestingly, the mean particle size of atorvastatin calcium increased with an increase in the boiling point of the organic solvent used (Fig. 3b). Thus, for atorvastatin particle formation via the SAS process, particle size was determined mainly by evaporation of the organic solvent into the antisolvent phase. Therefore, the properties of organic solvents such as polarity, boiling point, and solubility parameter are important variables in controlling particle formation of atorvastatin calcium using the SAS process. In the present study, acetone and THF were the better organic solvents for controlling nanoparticle formation of atorvastatin calcium.

Effect of Drug Solution Concentration The initial drug solution concentration is related to product yield and process efficacy in the SAS process. Acetone and THF were used to investigate the influence of initial drug solution concentration on the mean particle size and particle size distribution. Figure 4 displays the morphology of atorvastatin calcium precipitated from acetone and THF solutions of 200 or $300 \mathrm{mg} / \mathrm{mL}$. The mean particle size increased quantitatively with increasing drug solution concentration, suggesting that a lower concentration of drug solution precipitates particles of smaller size. This finding agrees with a previous report showing that an increased drug concentration in organic solvent produced a larger mean particle size in the SAS process. ${ }^{9,25)}$ These results can be explained in terms of nucleation and growth processes. When dilute solutions are injected, it takes longer to achieve saturation and precipitation; thus, nucleation is the prevailing mechanism, and smaller particles are formed. As shown in Table 1, at the higher drug concentration $(300 \mathrm{mg} / \mathrm{mL})$, the drug particles that precipitated from acetone and THF exhibited a narrower particle size distribution, with mean particle sizes of 179.7 and $348.9 \mathrm{~nm}$, respectively. Thus, from the

(b)

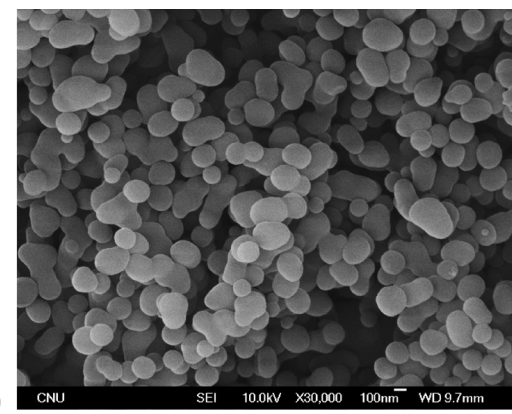

(d)

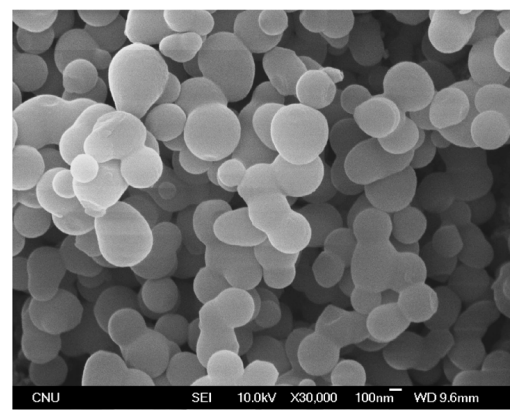

Fig. 4. SEM Images of Atorvastatin Calcium Precipitated from Acetone Solution of $200 \mathrm{mg} / \mathrm{mL}$ (a) or $300 \mathrm{mg} / \mathrm{mL}$ (b) and from THF Solution of $200 \mathrm{mg} / \mathrm{mL}$ (c) or $300 \mathrm{mg} / \mathrm{mL}$ (d) 


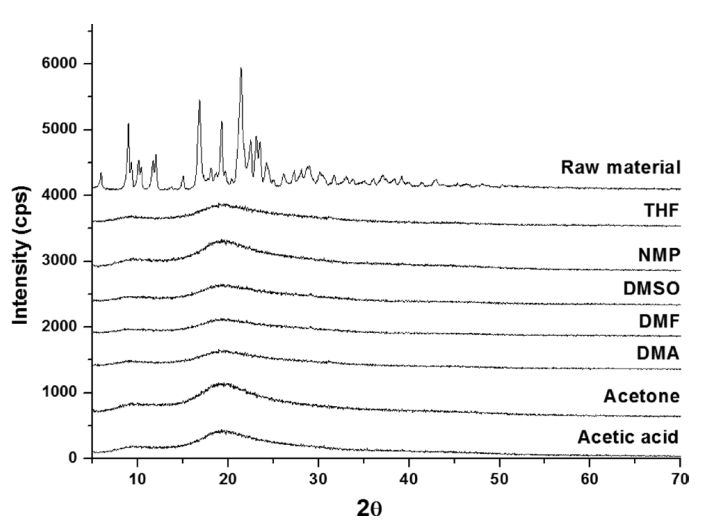

Fig. 5. X-Ray Diffraction Patterns

aspects of particle size and solvent toxicity, acetone was the better organic solvent for controlling nanoparticle formation of atorvastatin calcium.

Powder X-Ray Diffraction Analysis The X-ray diffraction patterns for samples of atorvastatin calcium unprocessed and processed by SAS are compared in Fig. 5. All samples of atorvastatin calcium lost their crystalline structure following the SAS process, as evidenced by the disappearance of the main peaks of unprocessed atorvastatin calcium. Consequently, the crystalline structure of atorvastatin calcium changed to an amorphous form during the SAS process.

\section{Conclusions}

In this study, amorphous atorvastatin calcium was precipitated from seven different solvents using the SAS process. By changing the solvent, we observed large variations in particle size and particle size distribution, accompanied by different particle morphologies. Among the seven solvents used, acetone was the better choice for controlling nanoparticle formation of atorvastatin calcium. Clearly, organic solvent properties such as polarity, boiling point, and solubility parameter are important variables for controlling nanoparticle formation of atorvastatin calcium using the SAS process.

Acknowledgments This work was supported by the Priority Research Centers Program through the National Research Foundation of Korea (NRF) funded by the Ministry of Education, Science and Technology (2009-0093815).

\section{References}

1) Pasquali I., Bettini R., Giordano F., Eur. J. Pharm. Sci., 27, 299-310 (2006).

2) Yeo S.-D., Kim M.-S., Lee J.-C., J. Supercrit. Fluids, 25, 143-154 (2003).

3) Reverchon E., J. Supercrit. Fluids, 15, 1-21 (1999).

4) Tenorio A., Gordillo M. D., Pereyra C., Martinez de la Ossa E. J., J. Supercrit. Fluids, 40, 308-316 (2007).

5) Costa M. S., Duarte A. R. C., Cardoso M. M., Duarte C. M. M., Int. J. Pharm., 328, 72-77 (2007).

6) Reverchon E., Della Porta G., J. Supercrit. Fluids, 26, 243-252 (2003).

7) Miguel F., Martin A., Gamse T., Cocero M. J., J. Supercrit. Fluids, 36, 225-235 (2006).

8) Cocero M. J., Ferrero S., J. Supercrit. Fluids, 22, 237-245 (2002).

9) Kim M.-S., Lee S., Park J.-S., Woo J.-S., Hwang S.-J., Powder Technol., 177, 64-70 (2007).

10) Kim M.-S., Jin S. J., Kim J.-S., Park H. J., Song H. S., Neubert R. H., Hwang S.-J., Eur. J. Pharm. Biopharm., 69, 454-465 (2008).

11) Kim J.-S., Kim M.-S., Park H.-J., Jin S. J., Lee S., Hwang S.-J., Int. J. Pharm., 359, 211-219 (2008).

12) Kordikowski A., Schenk A. P., Van Nielen R. M., Peters C. J., J. Supercrit. Fluids, 8, 205-216 (1995).

13) Adrian T., Maurer G., J. Chem. Eng. Data, 42, 668-672 (1997).

14) Gonzalez A. V., Tufeu R., Subra P., J. Chem. Eng. Data, 47, 492495 (2002).

15) Im J., Bae W. Lee J., Kim H., J. Chem. Eng. Data, 49, 35-37 (2004).

16) Reverchon E., Caputo G., Marco I. D., Ind. Eng. Chem. Res., 42, 6406-6414 (2003).

17) Bamberger A., Maurer G., J. Chem. Thermodyn., 32, 685-700 (2000).

18) Lazzaroni M. J., Bush D., Brown J. S., Eckert C. A., J. Chem. Eng. Data, 50, 60-65 (2005).

19) Reverchon E., Della Porta G., Di Trolio A., Pace S., Ind. Eng. Chem. Res., 37, 952-958 (1998).

20) Park S.-J., Jeon S.-Y., Yeo S.-D., Ind. Eng. Chem. Res., 45, $2287-$ 2293 (2006).

21) www.pirika.com. "Hansen Solubility Parameters (HSP) Application Notes," 〈http://pirika.com/NewHP/PirikaE2/ScCO2.html〉, cited 05 October, 2011.

22) Burke J., "Solubility Parameters: Theory and Application," Vol. III, ed. by Jensen C., The American Institue for Conservation, Ann Arbor, 1984.

23) Kröber H., Teipel U., J. Supercrit. Fluids, 22, 229-235 (2002).

24) Reverchon E., Della Porta G., Falivene M. G., J. Supercrit. Fluids, 17, 239-248 (2000).

25) Mukhopadhyay M., Dalvi S. V., J. Supercrit. Fluids, 30, 333-348 (2004).

26) Marcus Y., "The Properties of Solvents," Wiley Series in Solution Chemistry, John Wiley \& Sons, New York, 1998. 